\title{
Assessment of Thyroid Function in Major Thalassemia Patients above 12 Year of Age
}

\author{
Dr. Jyoti Prakash Yogi ${ }^{1}$, Dr. Mukesh Soni ${ }^{2}$, Dr. Prakash Keshwani ${ }^{3}$ \\ ${ }^{1}$ Residents, Department of Gen Medicine SMS Medical College/ RUHS, RAJ., India \\ ${ }^{2}$ Residents, Department of Gen Medicine SMS Medical College/ RUHS, RAJ., INDIA) \\ ${ }^{3}$ Sen. Prof. \& Unit Head, Department of Gen Medicine SMS Medical College/ RUHS, RAJ., INDIA)
}

\begin{abstract}
Thyroid dysfunctions in patients with beta-thalassemia are the result of iron toxicity to thyroid cells. The present study was conducted in 160 subjects divided into two groups -Group A comprised of 80 diagnosed cases of $\beta$-thalassemia major above 12 years of age receiving regular blood transfusions for more than last 3 years and at least 10 transfusions in a year. Group B comprised of age and sex matched 80 healthy individuals. We found that prevalence of hypothyroidism in patients with beta-thalassemia major was $20 \%$ patients, which was significantly $(p<0.0001)$ higher than the group $B$, in which prevalence of hypothyroidism was only $3.75 \%$.
\end{abstract}

Keywords: $\beta$-thalassemiamajor, Hypothyroidism

\section{Introduction}

Beta-thalassemia major (BTM) is a common health problem in the Africa, Southeast Asia and Indian subcontinent. Betathalassemia major is a hereditary, severe hemolytic anemia resulting from defects in synthesis of both $\beta$ chains of hemoglobin synthesis ${ }^{(1)}$. Lifelong blood transfusion is needed every 2 to 4 weeks, to maintain a hemoglobin level above $10 \mathrm{~g} / \mathrm{dl}$, as a lifesaving for these patients ${ }^{(2)}$. However, frequent blood transfusion can lead to iron overload, which may accumulate in various organs such as liver, heart, and endocrine glands due to the lack of physiological pathway for iron excretion in the body ${ }^{(3)}$. Complications related to iron overload include growth retardation and failure or delay of sexual maturation, dilated cardiomyopathy, arrhythmias, liver cirrhosis, diabetes mellitus, and insufficiency of the parathyroid, thyroid, pituitary, and, less commonly, adrenal glands. This massive accumulation of iron may cause organ dysfunction and failure, and ultimately death ${ }^{(2)}$. The gonadal axis is most sensitive to iron-induced damage followed by thyroid gland which appears to fail before the pituitarythyroid axis ${ }^{(4)}$.

Hypothyroidism in BTM patients is mainly due to infiltration and destruction of gland by iron. Iron overload and chronic tissue hypoxiahave a direct toxic effect on the thyroid gland. High concentrations of labile plasma iron and labile cell iron generates free radicals, and the production of reactive oxygen species may lead to cell and organ damage (5). Although rare but in severe iron overloaded $\beta$ thalassemic major patients, the anterior pituitary or hypothalamus may be damaged and regulatory hormonal secretion (TSH or TRH) may be disrupted leading to secondary hypothyroidism ${ }^{(4,9-11)}$.

With the introduction of iron chelators, especially the oral ones during the last decade, prognosis and survival in $\beta$ thalassemia major have improved but the endocrine complications have become more frequent in longer survivors of $\beta$-thalassemia major and substantially affect their quality of life ${ }^{(6)}$.
Hypothyroidism may create major cardiovascular changes, such as a decrease in cardiac output because of decrease in oxygen and substrate utilization, a decrease in cardiac contractility, a reduction in heart rate and an increase in peripheral vascular resistance ${ }^{(7)}$. Thyroid hormones may also play a critical role in growth and development in infants and as well as in young adults ${ }^{(8)}$. It is now clear that without optimal thyroid function, mood disturbance, cognitive impairment and other psychiatric symptoms can emerge. As the symptoms of hypothyroidism are non-specific, but the consequences affect virtually every organ system, an early systematic laboratory evaluation of thyroid function should be recommended in all thalassemic patients annually.

\section{Literature Survey}

Hypothyroidism can make an impact on morbidity and mortality of these patients. There are so many studies, directly or indirectly on thyroid dysfunctions in thalassemia major, but exact burden of the disease is still controversial $(4,10)$. In our study we tried to find out the thyroid dysfunction in patients with $\beta$-thalassemia major along with comparing the results with age and sex matched normal individuals.

\section{Material and Methods}

This hospital based case-control study was done in SMS Hospital, Jaipur from Oct. 2012 to Oct. 2013 in which 160 subjects was enrolled and was grouped into two; with 80 subjects in each.

Group A (Case group) - Patients of $\beta$-thalassemia major of more than 12 years of age receiving regular blood transfusions for more than last 3 years and at least 10 transfusions in a year.

Group B (Control group) - Age and sex matched apparently normal individuals. 


\section{International Journal of Science and Research (IJSR) \\ ISSN (Online): 2319-7064 \\ Index Copernicus Value (2015): 78.96 | Impact Factor (2015): 6.391}

All subjects were evaluated for complete physical examination including height and weight of these patients. Blood samples were taken for Complete Blood Counts, Peripheral Blood Film, Renal and Liver functions, Serum Iron, Serum Ferritin level estimation along with Thyroid Function Tests $\left(\mathrm{FT}_{3} \mathrm{FT}_{4} \mathrm{TSH}\right)$.

Blood samples were taken at least 2 weeks after the last transfusion. CBC was performed using the principle of 'Light scattering and fluorescin dye absorption' by 'sysmexxn 1000 ' with 5 parts differential count. Serum ferritin and thyroid function tests were done by 'Immulite 2000' as per protocol of immulite 2000 kits supplied by Siemens, Siemens Medical Solutions Diagnostic Ltd. UK using the principle of chemiluminiscent immunoassay.

The patients, who have serum FT3, FT4 and TSH in normal range were considered as normal or Euthyroid. The patients, who had raised serum TSH but normal serum FT3 and FT4 were categorized as subclinical hypothyroid. The patients, who had raised serum TSH level with reduced serum FT3 and FT4 were considered as overt hypothyroid. The normal hormonal values in our hospital lab were as below:-

\begin{tabular}{|c|c|}
\hline Serum FT3- & $2.3-4.2 \mathrm{pg} / \mathrm{ml}$ \\
\hline Serum FT4- & $0.89-1.76 \mathrm{ng} / \mathrm{ml}$ \\
\hline Serum TSH- & $0.4-5.5 \mathrm{uIU} / \mathrm{ml}$ \\
\hline
\end{tabular}

Data obtained from both groups were analyzed statistically by SPSS software. Various statistical tests were applied as according to their indication. A p-value less than 0.05 was considered statistically significant.

\section{Results and Discussions}

Table 1: Comparison of Mean Serum FT3 Level in Group A and B

\begin{tabular}{|c|c|c|c|}
\hline & Range & Mean Serum FT3 & $S D$ \\
\hline Group A & $1.86-3.96$ & 3.01 & 0.52 \\
\hline Group B & $1.96-3.98$ & 3.08 & 0.58 \\
\hline
\end{tabular}

$t=0.8881$ with 158 degrees of freedom: $P=0.3758$

Table 1 shows mean serum FT3 measurement and its comparison in group A and B. Although; mean serum FT3 level in group A $(3.01 \pm 0.52 \mathrm{pg} / \mathrm{ml})$ was slightly lower than in group B $(3.08 \pm 0.58 \mathrm{pg} / \mathrm{ml})$, but the difference was not statistically significant $(\mathrm{P}=0.3758)$.

Table 2: Comparison of Mean Serum FT4 Level in Group A and $\mathrm{B}$

\begin{tabular}{|c|c|c|c|}
\hline & Range & Mean Serum FT4 & SD \\
\hline Group A & $0.74-1.64$ & 1.14 & 0.18 \\
\hline Group B & $0.92-1.56$ & 1.16 & 0.16 \\
\hline
\end{tabular}

$t=0.6124$ with 158 degrees of freedom: $P=0.5412$

Table 2 shows mean serum FT4 measurement and its comparison in group A and B. Mean serum FT4 in group A was $1.14 \pm 0.18 \mathrm{ng} / \mathrm{ml}$ and in group B was $1.16 \pm 0.16 \mathrm{ng} / \mathrm{ml}$ and this difference was statistically not significant $(\mathrm{P}=$ $0.5412)$.
Table 3: Comparison of Mean TSH in Group A and Group $\mathrm{B}$

\begin{tabular}{|c|c|c|c|}
\hline & Range & Mean TSH & SD \\
\hline Group A & $1.57-18.78$ & 4.22 & 2.78 \\
\hline Group B & $1.12-8.24$ & 3.04 & 1.23 \\
\hline
\end{tabular}

$t=3.4466$ with 158 degrees of freedom: $P=0.0007$

Mean serum TSH level in patients of beta-thalassemia major was $4.22 \pm 2.78 \mathrm{uIU} / \mathrm{ml}$; which was significantly $(\mathrm{p}=0.0007)$ higher than mean serum TSH level $(3.04 \pm 1.23 \mathrm{uIU} / \mathrm{ml})$ in subjects of group B.

Table 4: Thyroid Function Status in Group A and B

\begin{tabular}{|l|c|c|c|c|}
\hline & \multicolumn{2}{|c|}{ Group A } & \multicolumn{2}{c|}{ Group B } \\
\hline Euthyroidism & 64 & $80 \%$ & 77 & $96.25 \%$ \\
\hline Subclinical Hypothyroidism & 11 & $13.75 \%$ & 03 & $3.75 \%$ \\
\hline Overt Hypothyroidism & 05 & $6.25 \%$ & - & - \\
\hline Total & 80 & $100 \%$ & 80 & $100 \%$ \\
\hline
\end{tabular}

Table 4 shows Thyroid function status in both groups. 64 $(80 \%)$ patients were having normal thyroid function in group A; whereas in group B, 77 subjects $(96.25 \%)$ were in Euthyroid state. Hypothyroidism was found only in 3 $(3.75 \%)$ subjects in group B; whereas in group A hypothyroidism was present in $16(20 \%)$ patients fout of which 11 patients (13.75\%) were having subclinical hypothyroidism and 5 patients $(6.25 \%)$ were having overt hypothyroidism\}. The difference in two groups was statistically significant $(\mathrm{P}=0.0001)$.

We found that in patients of $\beta$-thalassemia major, 7 out of 30 $(23 \%)$ females were hypothyroid and 9 out of $50(18 \%)$ males were hypothyroid. This difference was not statistically significant $(\mathrm{P}=0.5763)$ suggesting that sex is not a predisposing factor for development of hypothyroidism in patients of thalassemia.

\section{Conclusion}

We found that prevalence of hypothyroidism in patients with beta-thalassemia major was $20 \%$ patients, which was significantly $(p<0.0001)$ higher than the group $B$, in which prevalence of hypothyroidism was only $3.75 \%$. Early diagnosis and early therapy with blood transfusion predisposes for development of hypothyroidism in patients of beta-thalassemia major. Prevalence of hypothyroidism in patients with beta-thalassemia major is not dependent on sex of patients.

\section{Future Scope}

Our study has some limitations also. First, due to small duration of study period, it was difficult to perform a longitudinal or interventional study. Second, sample size was too small to establish a correlation between age, sex and serum ferritin level with thyroid dysfunctions. Our study may help the health-providers to suspect and diagnose thyroid dysfunctions at early stage in these patients with beta-thalassemia major. Further studies are needed to evaluate the longitudinal changes in thyroid dysfunction, and to find out any correlation between age, sex and serum ferritin level with thyroid dysfunction in $\beta$-thalassemia major. 


\section{International Journal of Science and Research (IJSR) \\ ISSN (Online): 2319-7064}

Index Copernicus Value (2015): 78.96 | Impact Factor (2015): 6.391

\section{References}

[1] Modell B, Khan M, Darlison M, King A, Layton M, Old J, Petrou M, Varnavides L, 2001: A national register for surveillance of inherited disorders: beta thalassemia in the United Kingdom. Bulletin of the WHO 79:10061013.

[2] Rund D, Rachmilewitz E, 2005: Beta-thalassemia. N Engl J Med 353:1135-1146.

[3] Olivieri NF, 1999: The beta-thalassemias. N Engl J Med 341:99-109.

[4] Landau H, Matoth I, Landau-Cordova Z, Goldfarb A, Rachmilewitz EA, Glaser B. (1993). Cross-sectional and longitudinal study of the pituitary-thyroid axis in patients with thalassaemia major, ClinEndocrinol (Oxf), Vol.38 (1), pp. 55-61.

[5] Esposito BP, Breuer W, Sirankapracha P, Pootrakul P, Hershko C, Cabantchik ZI. (2003). labile plasma iron in iron overload: redox activity and susceptibility to chelation. Blood, Vol.102 (7), pp.2670-7.

[6] Telfer PT, Warburton F, Christou S, Hadjigavriel M, Sitarou M, Kolnagou A. (2009). Improved survival in thalassemia major patients on switching, from desferrioxamine to combined chelation therapy with desferrioxamine and deferiprone. Haematologica, Vol. 94(12), pp. 1777-8.

[7] Klein I, Danzi S. (2007) Thyroid disease and the heart. Circulation, vol. 116, pp. 1725.

[8] Bernal J. (2002) Action of thyroid hormone in brain, Journal of Endocrinological Investigation, Vol. 25, pp. 268-288.

[9] Borgna-Pignatti C, Cappellini MD, De Stefano P, Del Vecchio GC, Forni GL, Gamberini MR, Ghilardi R, Origa R, Piga A, Romeo MA, Zhao $\mathrm{H}$, Cnaan A: Survival and complications in thalassemia. Ann $N Y$ AcadSci2005, 1054:40-47

[10] KallistheniFarmaki (2012). Hypothyroidism in Thalassemia, Hypothyroidism - Influences and Treatments, Dr. Drahomira Springer (Ed.), 5:97-110

[11] Gabutti V, Piga A: Results of long-term iron-chelating therapy. ActaHaematol1996, 95:26-36.

\section{Author Profile}

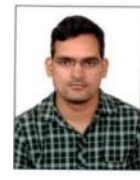

Dr. J. P. Yogi received the graduation and post graduation degree in general medicine from SMS Medical college jaipur Rajasthan in 2011 and 2014 respectively. During 2011-2014 he stayed in SMS Medical College circumference.

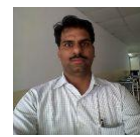

Dr. Mukesh Soni received the graduation and post graduation degree in general medicine from SMS Medical college jaipur Rajasthan in 2011 and 2014 respectively. During 2011-2014 he stayed in SMS Medical College circumference.

Dr. Prakash Keshwani working as a Sen. Prof. \& Unit Head, Department of Gen Medicine SMS Medical College RUHS, RAJ., INDIA till today. 